\title{
An Analysis of Intercultural Sensitivity and Ethnocentrism Levels of Teacher Candidates
}

\author{
${ }^{1}$ Serkan DEMiR, ${ }^{2}$ Elif ÜSTÜN \\ ${ }^{1}$ Beşiktaş Bilim ve Sanat Merkezi, ${ }^{2}$ Fahrettin Kerim Gökay Anadolu Lisesi
}

\begin{abstract}
The aim of this research is to find out the effects of two variables on primary and secondary school teacher candidates' intercultural sensitivity and ethnocentrism levels. One of the variables is the subject matter they studied at university and the other variable is gender. The research model is descriptive. The study group consists of 314 volunteer teacher candidates who attended a private course to prepare for Public Personnel Selection Examination (aka. KPSS) during 2014-2015 academic year. Intercultural sensitivity level of teacher candidates was measured by Intercultural Sensitivity Scale developed by Chen and Starosta (2000) and their ethnocentrism level was measured by Ethnocentrism Scale developed by Neuliep and McCroskey (1997). Linguistic equivalence, validity and reliability studies of two scales were done by Ustun (2011). One way analysis of variance (ANOVA) and independent samples $T$ test were used to analyze the data. Findings of the research showed that there is a statistically significant difference between teacher candidates' intercultural sensitivity levels in terms of their departments at university, type of high school that they attended. Findings also showed that there is a statistically significant difference between teacher candidates' ethnocentrism levels in terms of their departments at university.
\end{abstract}

Keywords: Intercultural sensitivity, Ethnocentrism, Teacher candidate

Inönü University

Journal of the Faculty of Education

Vol 18, No 3, 2017

pp. 01-11

DOI: $10.17679 /$ inuefd. 354129

\section{Suggested Citation}

Received : 31.07.2016

Revision1 : 31.05.2017

Accepted : 15.08.2017

Demir, S., Üstün, E. (2017). Öğretmen Adaylarının, Kültürlerarası Duyarlııı ve Etnik Merkezcilik Düzeylerinin İncelenmesi, İnönü Üniversitesi Eğitim Fakültesi Dergisi 18(3), 01-11. DOI: 10.17679/inuefd.354129 


\section{EXTENDED ABSTRACT}

\section{Introduction}

Intercultural communication competence is comprised of three dimensions, including intercultural awareness (cognitive), intercultural sensitivity (affective), and intercultural adroitness (behavioural) (Chen ve Starosta, 1996; Davis, 2005). Development of these three dimensions helps individuals to be global citizens who can empathize with people from different cultures besides being aware of both their own cultures and the other cultures (Eğinli, 2011).In accordance with the above-mentioned needs, Ministry of National Education have updated the primary and secondary school curricula gradually since 2004-2005 academic year; and goals and objectives related to intercultural communication competence have been included in some of these curricula. The aim is to enable students to learn about different cultures and to develop respect and tolerance towards cultural differences. In other words, the development of intercultural awareness and sensitivity is aimed in the new curricula.In the process of developing intercultural awareness and sensitivity the most important role, alongside the role of curricula and textbooks, is teachers' role. In this respect, the extent to which teachers have intercultural communication competence is an issue to focus on. A considerable amount of literature which aims to investigate teachers' and teacher candidates' level of intercultural communication competence has been published abroad over the last decade. However, there has been relatively little literature published on this issue in Turkey.

\section{Purpose}

The purpose of this study is to examine the variables expected to affect teacher candidates' intercultural sensivity levels, which is the affective dimension of intercultural communication competence according to Chen and Starosta (1996, 353-383), and to examine the variables expected to affect their ethnocentrism levels which is seen as a barrier to intercultural communication. English, Social Sciences, Turkish Language and Literature and Primary School teacher candidates were included in this study since they are expected to develop students' intercultural communication competence according to the new curricula. This descriptive study is expected to contribute to the regulation of pre-service and in-service programs which might be conducted by teacher training institutions and schools with the aim of developing intercultural sensitivity and preventing ethnocentrism.

\section{Method}

This study in which teacher candidates' intercultural sensitivity and ethnocentrism levels were compared according to some variables is within the scope of descriptive research design. In a descriptive research design, the aim is to observe the situation without trying to change it (Karasar, 2007, 77). The study group consists of 348 volunteer teacher candidates who attended a private course in Istanbul to prepare for Public Personnel Selection Examination (aka. KPSS) during 2014-2015 academic year. Goals and objectives related to intercultural communication competence are clearly defined in Turkish (1-5th grade), Turkish Language and Literature, English and Social Sciences Curricula. For this reason, senior students and graduates of the departments of Primary Education, Turkish Language and Literature Teaching, English Language Teaching and Social Sciences Teaching were included in this study. Intercultural sensitivity level of teacher candidates was measured by Intercultural Sensitivity Scale developed by Chen and Starosta (2000) and their ethnocentrism level was measured by Ethnocentrism Scale developed by Neuliep and McCroskey (1997). Linguistic equivalence, validity and reliability studies of two scales were done by Ustun (2011). The Intercultural Sensitivity Scale, which is developed by Chen and Starosta (2000), is a 24-item instrument with a Likert scale from 1-5. The scale is comprised of five dimensions which are Interaction Engagement (items $1,11,13,21,22,23,24)$, Respect for Cultural Differences (items 2, 7, 8, 16, 18, 20), Interaction Confidence (items 3, 4, 5, 6, 10), Interaction Enjoyment (items 9, 12, 15) and Interaction Attentiveness (items 14, 17, 19). Items $2,4,7,9,12,15,18,20,22$ are reverse scored. The Cronbach Alpha reliability coefficient of the original scale was .86 and .88 in two separate studies.

In order to test the validity of Turkish form of the scale, confirmatory factor analysis was conducted and the total variance explained by the 5 subscales was calculated as $63 \%$. However, due to the fact that the factor loads of 3 items did not match, the Turkish form of the scale was used as a single-factor scale and the factor analysis was repeated. After the final factor analysis one item was removed from the scale due to having low 
factor load. Therefore, Turkish form of Intercultural Sensitivity Scale included 23 items. Cronbach Alpha reliability of this form was .90. The Ethnocentrism Scale, which is developed by Neuliep ve McCroskey (1997), is a 22 -item instrument with a Likert scale from 1-5. Items 4, 7, 9, 12, 15, 19 are reverse scored. The Cronbach Alpha reliability of the original scale was .92. The original Ethnocentrism Scale is a single-factor scale. After the confirmatory factor analysis, 2 items were removed from the scale as they their factor loads did not match. Thus, Turkish form of Ethnocentrism Scale included 20 items. Cronbach Alpha reliability of this form was .82. In this study, teacher candidates' intercultural sensitivity and ethnocentrism levels were compared according to some variables. One way analysis of variance (ANOVA) and independent samples T test were used to analyze the data.

\section{Findings}

Findings of the research showed that there is a statistically significant difference between teacher candidates' intercultural sensitivity levels in terms of their departments at university, size of their hometowns, type of high school that they attended, their going abroad experiences and having friends from different national or cultural backgrounds. Findings also showed that there is a statistically significant difference between teacher candidates' ethnocentrism levels in terms of their departments at university, gender, size of their hometowns, their going abroad experiences.

\section{Discussion \& Conclusion}

Teachers, architects of societies, are expected to be competent in social skills before the other members of the society. In this context, teacher training programs should include courses which aim to improve teacher candidates' intercultural communication competence. In addition, through in-service training, primary and secondary school teachers should be informed about the goals and objectives related to intercultural communication skills and they should be provided with the opportunity to discuss the ways in which these skills can be improved effectively. The present research has been focused on quantitative data. Further research should concentrate on qualitative data in order to better understand the thoughts and attitudes of participants on cultural differences. 


\title{
Öğretmen Adaylarının Kültürlerarası Duyarlılık ve Etnikmerkezcilik Düzeylerinin Incelenmesi
}

\author{
${ }^{1}$ Serkan DEMiR, ${ }^{2}$ Elif ÜSTÜN \\ ${ }^{1}$ Beşiktaş Bilim ve Sanat Merkezi, ${ }^{2}$ Fahrettin Kerim Gökay Anadolu Lisesi
}

\section{Öz}

Bu araştırmanın amacı, ilköğretim ve ortaöğretim kurumlarında görev yapmak üzere yetiştirilen öğretmen adaylarının kültürlerarası duyarlıık ve etnikmerkezcilik düzeylerini bölüm ve mezun oldukları lise göre belirlenmesidir. Araştırmanın modeli betimsel araştırma kapsamına giren genel tarama modelidir. Araştırmanın çalışma grubu, 2014-2015 eğitim öğretim yılında özel bir dershaneye kayıtlı olup kamu personeli sınavına hazırlanan ve araştırmaya gönüllü olarak katılan 314 ögretmen adayıdır. Öğretmen adaylarının kültürlerarası duyarlıık düzeyleri Chen ve Starosta (2000) tarafından geliştirilen Kültürlerarası Duyarlılı Ölçeği; etnikmerkezcilik düzeyleri ise Neuliep ve McCroskey (1997) tarafından geliştirilen Etnikmerkezcilik Ölçeği ile ölçülmüştür. Her iki ölçeğin geçerlik ve güvenirlik çalışmaları Üstün (2011) tarafından yapılmıştır. Verilerin çözümlenmesi sırasında, tek faktörlü varyans analizi (ANOVA) uygulanmıştır. Araştırma sonucunda elde edilen bulgular, ögretmen adaylarının kültürlerarası duyarlıık düzeyleri arasında bölümlerine, mezun oldukları lise türlerine göre istatistiksel olarak anlamlı fark olduğunu ortaya koymuştur. Öğretmen adaylarının etnikmerkezcilik düzeyleri arasında ise bölümlerine göre istatistiksel olarak anlamlı fark olduğu görülmüştür.

Anahtar Kelimeler: Kültürlerarası Duyarlılık, Etnikmerkezcilik, Öğretmen Adayı

İnönü Üniversitesi

Eğitim Fakültesi Dergisi

Cilt 18, Sayı 3, 2017

ss. $01-11$

DOI: $10.17679 /$ inuefd. 354129

\section{Önerilen Atıf}

Demir, S., Üstün, E. (2017). Öğretmen Adaylarının, Kültürlerarası Duyarlılık ve Etnik Merkezcilik Düzeylerinin İncelenmesi Inönü Üniversitesi Eğitim Fakültesi Dergisi, 18(3), 01-11. DOI: 10.17679/inuefd.354129 


\section{Giriş}

Küreselleşme ve modern teknolojinin değişen doğası, toplumların kendilerini dış etkilerden yalıtmasını neredeyse imkânsız hale getirmektedir. Kültürel çeşitliliğin tüm toplumları farklı derecelerde de olsa nitelemesi sebebiyle bu toplumların onunla beraber yaşamanın hatta ondan yararlanmanın yolunu bulmaları gerekmektedir (Parekh, 2002). Aynı coğrafi sınırlar içindeki kültürel çeşitlilikten yararlanmanın ve farklı ülkelerden bireylerle etkili iletişim kurup ülkeler arası barışı ve alışverişi sağlamanın yolu kültürlerarası iletişim yeterliliğini geliştirmeyi hedefleyen bir eğitim sisteminden geçmektedir.

Kültürlerarası iletişim, farklı kültürel özelliklere sahip bireyler arasında gerçekleşen etkileşim süreci olarak açıklanmaktadır (Coşkun, 2006). Bu süreçte iletişimde yanlış algılamaların en aza inmesi ve iletişimin etkin olarak kurulabilmesi ise kültürlerarası iletişim yeterliliğinin gelişimi ile mümkün olmaktadır. Kültürlerarası iletişim yeterliliği; bilişsel (kültürel farkındalık), duyuşsal (kültürlerarası duyarlılık) ve davranışsal (kültürlerarası beceriklilik) olmak üzere üç boyuttan oluşmaktadır (Chen \& Starosta, 2005). Kültürlerarası yeterliliği oluşturan bu üç boyutun gelişimi; bireylerin kendi kültürünü ve farklı kültürleri tanıyan; farklı kültürler ile empati kurabilen küresel vatandaşlar olmalarına yardımcı olmaktadır (Eğinli, 2011).

Kültürlerarası iletişim yeterliliğinin duyuşsal boyutunu oluşturan kültürlerarası duyarlılık ise kültürlerarası farklılıkları anlamada, kabul etmede ve takdir etmede kendi motivasyonunu sağlamak için gerekli olan aktif istek olarak tanımlanmaktadır (Bulduk, Tosun \& Ardıç, 2011). Başka bir tanım ile kültürlerarası duyarlılık; kültürel farklılıklara ve farklı kültürlerden insanların bakış açılarına karşı duyarlı olmayı ifade etmektedir (Bhawuk \& Brislin, 1992).

Kültürlerarası iletişim yeterliliğini oluşturan becerilerin geliştirilmesi, kültürlerarası çatışmaları önlemek adına önemli bir çabadır. Bununla birlikte, kültürlerarası iletişimi engelleyen faktörlerin belirlenip bu faktörlere karşı önlemler alınması da çatışmaları önlemede önemli bir paya sahiptir. Kültürlerarası iletişimi engelleyen faktörlerden biri de etnikmerkezciliktir.

Etnikmerkezcilik (ethnocentrism), farklı kültürel, etnik, dinsel ve bölgesel altyapılara sahip bireyler arasındaki iletişimi engelleyen unsurlardan biridir (Neuliep \& McCroskey, 1997). Sumner (1906), etnikmerkezcilik kavramını, bireyin kendi kültürünü her şeyin merkezine koyması ve diğer kültürleri, kendi kültürünü ölçüt alarak sınıflaması olarak tanımlamıştır. Etnikmerkezci birey, kendini, üyesi olduğu grubu ve kültürü evrenin merkezine yerleştirir ve diğerlerinin yerini buna göre belirler. Grup-dışı olanlardan, kendine en çok benzeyenleri en yakına, diğerlerini aralarındaki farklılığın derecesine göre daha uzağa yerleştirir (Kartarı, 2003). Başka bir ifadeyle, etnikmerkezcilik, bireyin kendi kültürünün üstünlüğüne inanması ve başka kültürleri kendi kültürünün değerleriyle yargılamasıdır (Jandt, 1995).

Sık göç alan toplumların kültürel çeşitliliği demokratik bir şekilde yönetebilme konusunda çeşitli girişimlerde bulundukları ve uzun bir süreç sonunda çokkültürlülük ve kültürlerarasılık gibi kavramlar üzerinde yoğunlaştıkları bilinmektedir. Bu toplumlarda aynı zamanda çokkültürlü eğitim ve kültürlerarası eğitim konularında pek çok bilimsel çalışmanın yapıldığı görülmektedir. Coşkun'un (2006) belirttiği gibi, değişik ülkelerdeki Osmanlı mirası; Anadolu'daki çokkültürlü, çok dilli ve çok dinli mozaik; yurtdışına işgücü göçü; yurtdışına yapılacak ekonomik açılımlar vb. nedenlerden dolayı Türkiye'de de çokkültürlü ve kültürlerarası eğitimin üzerinde durulmalıdır.

Bu ihtiyaç çerçevesinde, Milli Eğitim Bakanlığı'nın 2004-2005 eğitim öğretim yılından itibaren, kademeli olarak yenilediği ilköğretim ve ortaöğretim programlarının bazılarında kültürlerarası iletişim yeterliliğini geliştirmeye yönelik genel amaç ve kazanımlara yer verildiği görülmektedir. Bu kazanımlar, genel olarak öğrencilerin farklı kültürleri tanımaları; kültürel farklııklara karşı saygı ve hoşgörü geliştirmelerini sağlamaya yöneliktir. Başka bir ifadeyle, yenilenen öğretim programlarında kültürlerarası farkındalık ve kültürlerarası duyarlılık becerilerini geliştirmeye yönelik genel amaç ve kazanımlara yer verilmiştir. Bu becerilerin kazandırılmasında öğretim programları ve ders kitaplarının rolünün yanında belki de en önemli rol o derslerin öğretmenlerine düşmektedir. Öğrencilere kültürlerarası farkındalık ve duyarlılık becerilerini kazandırması beklenen öğretmenlerin bu becerilere ne derece sahip oldukları ise üzerinde durulması gereken noktalardan biridir. 
Öğretmenlerin ve öğretmen adaylarının kültürlerarası iletişim yeterlilikleri konusunda yurtdışında yapılmış pek çok çalışmaya rastlamak mümkündür. Bu çalışmaların büyük bir bölümünün son 10 yıl içerisinde yapılmış olduğu görülmektedir. Türkiye'de ise öğretmenlerin ve öğretmen adaylarının kültürlerarası iletişim yeterlilik düzeylerini konu alan çok az çalışmanın olduğu dikkat çekmektedir.

Bu araştırmada, Chen ve Starosta'nın (1996) sınıflamasına göre kültürlerarası iletişim yeterliliğinin duyuşsal boyutunu ifade eden kültürlerarası duyarlılık becerisinin yanı sıra kültürlerarası iletişimi engelleyen unsurlardan biri olarak görülen etnikmerkezciliği etkileyebileceği düşünülen değişkenler incelenmiştir. Bu araştırmanın amacı, İngilizce, Din Kültürü, Türk Dili ve Edebiyatı ve Sınıf Öğretmenliği bölümlerinde öğrenim görmekte olan öğretmen adaylarının, göreve başladıkları zaman öğrencilere kazandırmaları beklenen kültürlerarası duyarlılık becerisine ne derece sahip olduklarını ve kültürlerarası iletişimin önünde bir engel olan etnikmerkezcilik düzeylerinin ne olduğunu mezun oldukları bölümlere ve mezun oldukları lise türüne göre incelemektir. Ayrıca betimsel nitelikte olan bu araştırmanın, öğretmen yetiştiren kurumlar ile öğretmen istihdam eden kurumların kültürlerarası iletişim yeterliliğini geliştirme ve etnikmerkezciliği önlemeye yönelik hizmet öncesi ve hizmetiçi programlarının düzenlenmesine katkıda bulunacağı düşünülmektedir.

Bu genel amaçlar doğrultusunda araştırmada aşağıdaki sorulara yanıt aranmıştır:

1.Bölümlerine göre öğretmen adaylarının kültürlerarası duyarlılık düzeyleri arasında anlamlı fark var mıdır?

2.Bölümlerine göre öğretmen adaylarının etnikmerkezcilik düzeyleri arasında anlamlı fark var mıdır?

3.Öğretmen adaylarının mezun oldukları lise türüne göre duyarlılık ve etnikmerkezcilik düzeyleri arasında anlamlı fark var mıdır?

\section{YÖNTEM}

\section{Araştırmanın Modeli}

Öğretmen adaylarının kültürlerarası duyarlılık ve etnikmerkezcilik düzeylerinin bazı değişkenlere göre karşılaştırıldığı bu araştırma, betimsel araştırma kapsamındaki genel tarama modelindedir. Tarama modellerinde, araştırmaya konu olan olay, birey ya da nesne var olduğu şekliyle betimlenmeye çalışılır (Karasar, 2007).

\section{Araştırmanın Çalışma Grubu}

Bu araştırma 2014-2015 öğretim yılında İstanbul ilinde özel bir dershaneye kayıtlı olup Kamu Personeli Seçme Sınavına hazırlanan 4.sınıfta öğrenim gören ve mezun durumundaki 314 öğretmen adayı ile gerçekleştirilmiştir. Tablo 1. ve Tablo 2. de araştırmaya katılan öğretmen adaylarının demografik nitelikleri sunulmuştur.

Tablo 1.

Öğretmen adaylarının mezun oldukları bölümlere ilişkin özellikler

\begin{tabular}{lcccc}
\hline & Kadın & Erkek & $\mathrm{f}$ & $\%$ \\
\hline Sinıf Öğretmenliği & 48 & 29 & 77 & 22.1 \\
Din Kültürü ve Ahlak Bilgisi Öğretmenliği & 41 & 19 & 60 & 19.1 \\
Türk Dili ve Edebiyatı Öğretmenliği & 62 & 53 & 115 & 33.0 \\
İngilizce Öğretmenliği & 39 & 23 & 62 & 22.9 \\
\hline
\end{tabular}

Tablo 1'de görüldüğü gibi araştırmaya katılan öğretmen adaylarının 77'si sınıf öğretmenliği, 60'ı Din Kültürü ve Ahlak Bilgisi Öğretmenliği, 115'i Türk Dili ve Edebiyatı Öğretmenliği ve 62'si İngilizce öğretmenliği bölümünden mezun ve mezun durumdadır. 
Tablo 2.

Öğretmen adaylarının mezun oldukları lise türlerine ilişkin özellikler

\begin{tabular}{lcc}
\hline & $\mathrm{f}$ & $\%$ \\
\hline Düz Lise & 86 & 27.8 \\
Öğretmen Lisesi & 61 & 19.4 \\
Anadolu/Süper Lise & 74 & 23.5 \\
İmam Hatip Lisesi & 77 & 24.5 \\
Özel Lise & 16 & 5.0 \\
\hline
\end{tabular}

Tablo 2'de görüldüğü gibi araştırmaya katılan öğretmen adaylarının 86'sı düz lise, 61'i öğretmen lisesi, 74'ü anadolu/süper lisesi, 77 'si imam hatip lisesi ve 16 'sı özel lise mezunudur.

\section{Veri Toplama Araçları}

Bu araştırmada öğretmen adaylarının kültürlerarası duyarlılık düzeylerini ölçmek amacıyla Kültürler Arası Duyarlık Ölçeği; etnikmerkeziyetçilik düzeylerini ölçmek amacıyla ise Etnikmerkezcilik Ölçeği kullanılmıştır.

\section{Kültürrlerarası Duyarlılık Ölçeği}

Öğretmen adaylarının kültürlerarası duyarlılık düzeylerini ölçmek için, Chen ve Starosta (2000) tarafından geliştirilen Kıran (2011) tarafından Türkçeye uyarlanması amacıyla sırasıyla dil eşdeğerliği, geçerlik ve güvenirlik çalışmaları yapılan 24 maddelik $5^{\prime}$ li Likert tipi Kültürlerarası Duyarlılık Ölçeği kullanılmıştır. Ölçeğin, Kültürlerarası Etkileşime Katılım (1, 11, 13, 21, 22, 23, 24. maddeler), Kültürel Farklılıklara Saygı Duyma $(2,7$, 8, 16,18, 20. maddeler), Kültürlerarası Etkileşimde Özgüven (3，4，5，6，10. maddeler), Kültürlerarası Etkileşimden Zevk Alma (9, 12, 15. maddeler), Kültürlerarası Etkileşime Özen Gösterme (14, 17, 19. maddeler) olmak üzere toplam 5 alt ölçeği bulunmaktadır. 2, 4, 7, 9, 12, 15, 18, 20 ve 22. maddeler ters çevrilerek puanlanmaktadır. Orijinal ölçeğin güvenirlik çalışması Kıran (2011) tarafından gerçekleştirilen iki ayrı uygulamada hesaplanan Cronbach Alpha katsayıları .86 ve $.88^{\prime}$ dir.

\section{Etnikmerkezcilik Ölçeği}

Öğretmen adaylarının etnikmerkezcilik düzeylerini ölçmek için Neuliep ve McCroskey (1997) tarafından geliştirilen Kıran (2011) tarafından Türkçeye uyarlanması amacıyla sırasıyla dil eşdeğerliği, geçerlik ve güvenirlik çalışmaları yapılan 22 maddelik 5 'li Likert tipi Etnikmerkezcilik Ölçeği kullanılmıştır. Ölçekte yer alan 4, 7, 9, 12, 15 ve 19. maddeler ters cevrilerek puanlanmaktadır. Orijinal ölçeğin Kıran (2011) tarafından yapılan güvenirlik çalışmasında Cronbach Alfa katsayısı .92 olarak bulunmuştur. Geçerlik çalışması kapsamında yapılan faktör analizi sonucunda 10. ve 19. maddelerin faktör yüklerinin .30'un altında olması nedeniyle bu maddeler ölçekten çıkarılmıştır. Geriye kalan 20 madde dil eşdeğerliği, geçerlik ve güvenirlik çalışmaları sırasında kabul edilebilir değerler gösterdikleri için ölçekte aynen yer almıştır.

\section{Verilerin Çözümlenmesi}

Ölçeğin uygulanması sonucu elde edilen veriler SPSS 17 istatistik programı ile çözümlenmiştir. Araştırmanın alt problemleriyle ilişki olarak öğretmen adaylarının kültürlerarası duyarlılık ve etnikmerkezcilik düzeyleri arasında bazı değişkenlere göre istatistiksel olarak anlamlı fark olup olmadığı incelenmiştir. Bu sebeple, çok değişkenli varyans analizi (ANOVA) yapılmıştır. Gruplar arası anlamlı farklıı̆̆ın olduğu durumlarda bu farkın hangi gruplardan kaynaklandığını belirlemek amacıyla da Scheffe testi uygulanmıştır.

\section{BULGULAR}

\section{Birinci Alt Probleme iliş̧kin Bulgular}

Araştırmanın birinci alt problemi "Bölümlerine göre öğretmen adaylarının kültürlerarası duyarlılık düzeyleri arasında anlamlı fark var mıdır?" şeklinde ifade edilmiştir. Araştırmanın birinci alt problemine ilişkin öğretmen adaylarının "Kültürlerarası Duyarlık Ölçeği"nden almış oldukları puan ortalamalarının birbirine yakın olduğu, ancak en yüksek puan ortalamasının İngilizce Öğretmenliği Bölümü (Xi: 93.27) öğretmen adayları, en düşük 
puan ortalamasının ise Türk Dili ve Edebiyatı Bölümü ( Xs:87.73) öğretmen adaylarının aldıkları görülmüştür. Grup varyansların homojenliğini test etmek için yapılan Levene testi sonucunda, grup varyanslarının eşit olduğu belirᄀlenmiştir [F(3-314):1.36,p>.05]. Tablo 3'de öğretmen adaylarının kültürlerarası duyarlılık düzeyleri arasında bölümlerine göre anlamlı fark olup olmadığını belirlemek amacıyla yapılan ANOVA değerleri sunulmuştur.

Tablo 3.

Bölüm Değişkenine Göre Öğretmen Adaylarının Kültürlerarası Duyarlılık Düzeylerine iliş̧kin Anova Değerleri

\begin{tabular}{llllll}
\hline & $\begin{array}{l}\text { Kareler } \\
\text { Toplamı }\end{array}$ & $\mathrm{df}$ & $\begin{array}{l}\text { Kareler } \\
\text { Ortalaması }\end{array}$ & $\mathrm{F}$ & $\mathrm{P}$ \\
\hline Gruplar & 4.86 & 3 & 1.62 & 3.11 & .01 \\
Arası & & 310 & 0.52 & & \\
Grup İçi & 163.85 & 313 & & & \\
Toplam & 168.71 & & & \\
\hline
\end{tabular}

Tablo 3'de görüldüğü gibi öğretmen adaylarının bölümlerine göre kültürlerarası duyarlılık düzeyleri puanları arasında anlamlı bir farkın olduğu görülmektedir. $[F(3-310)=3.11, p<0.05]$. Bu farkın hangi gruplardan kaynaklandığını belirlemek amacıyla yapılan Scheffe testi bulgularına göre bu fark Türk Dili ve Edebiyatı Öğretmenliği Bölümü adayları ile İngilizce Öğretmenliği Bölümü öğretmen adayları arasında İngilizce öğretmenliği bölümü öğretmen adaylarının lehine anlamlı fark bulunmaktadır $(p<.05)$. Ayrıca Sınıf Öğretmenliği Bölümü adayları ile yalnızca İngilizce Öğretmenliği Bölümü öğretmen adayları arasında İngilizce Öğretmenliği Bölümü adaylarının lehine anlamlı fark bulunmaktadır.

\section{İkinci Alt Probleme İlişkin Bulgular}

Araştırmanın ikinci alt problemi "Bölümlerine göre öğretmen adaylarının etnikmerkezcilik düzeyleri arasında anlamlı fark var mıdır?" şeklinde ifade edilmiştir. Araştırmanın ikinci alt problemine ilişkin öğretmen adaylarının "Etnikmerkezcilik Ölçeği"nden almış oldukları puan ortalamalarının birbirine yakın olduğu, ancak en yüksek puan ortalamasının Din Kültürü ve Ahlak Bilgisi Bölümü (Xd: 46.35) öğretmen adayları, en düşük puan ortalamasının ise İngilizce Öğretmenliği Bölümü (Xi:3.46) öğretmen adaylarının aldıkları görülmüştür. Grup varyansların homojenliğini test etmek için yapılan Levene testi sonucunda, grup varyanslarının eşit olduğu belir ᄀlenmiştir [F(3-314):0.83,p> .05]. Tablo 4'de öğretmen adaylarının kültürlerarası duyarlılık düzeyleri arasında bölümlerine göre anlamlı fark olup olmadığını belirlemek amacıyla yapılan ANOVA değerleri sunulmuştur.

Tablo 4.

Bölüm Değişkenine Göre Öğretmen Adaylarının Etnikmerkeziyetcilik Düzeylerine İlişkin Anova Değerleri

\begin{tabular}{llllll} 
& $\begin{array}{l}\text { Kareler } \\
\text { Toplamı }\end{array}$ & df & $\begin{array}{l}\text { Kareler } \\
\text { Ortalamas1 }\end{array}$ & F & P \\
\hline $\begin{array}{l}\text { Gruplar } \\
\text { Aras1 }\end{array}$ & 5.21 & 3 & 1.73 & 3.08 & .01 \\
$\begin{array}{l}\text { Grup İci } \\
\text { Toplam }\end{array}$ & 174.83 & 310 & 0.56 & & \\
\hline
\end{tabular}

Tablo 4'de görüldüğü gibi öğretmen adaylarının bölümlerine göre etnikmerkeziyetçilik puanları arasında anlamlı bir farkın olduğu görülmektedir. $[F(3-314)=3.08, p<0.05]$. Bu farkın hangi gruplardan kaynaklandığını belirlemek amacıyla yapılan Scheffe testi bulgularına göre bu fark Din Kültürü ve Ahlak Bilgisi Bölümü öğretmen adayları ile İngilizce Öğretmenliği Bölümü öğretmen adayları arasında Din Kültürü ve Ahlak Bilgisi Bölümü öğretmen adayları lehine anlamlı fark bulunmaktadır. 


\section{Üçüncü Alt Probleme ilişkin Bulgular}

Araştırmanın üçüncü alt problemi "Öğretmen adaylarının mezun oldukları lise türüne göre öğretmen adaylarının kültürlerarası duyarlılık ve etnikmerkezcilik düzeyleri arasında anlamlı fark var mıdır?" şeklinde ifade edilmiştir.

Öğretmen adaylarının üçüncü alt problem bağlamında ölçeklerden aldıkları toplam puanlara ait ortalama ve standart sapma değerleri göre, kültürlerarası duyarlılık düzeyi en yüksek grup özel liselerden mezun olanlar (X: 96.28); en düşük grup ise düz lise mezunlarıdır (X: 87.39). Düz lise mezunları ile Anadolu lisesi ve süper lise mezunlarının ortalamalarının birbirine çok yakın olduğu görülmektedir. Diğer yandan, ortalamalara göre etnikmerkezcilik düzeyi en yüksek grubun imam hatip lisesi mezunları (X: 46.58); en düşük grubun ise özel lise mezunları (42.13) olduğu görülmektedir.

Verilerin normal dağılım gösterip göstermediklerini test etmek için yapılan Kolmogorov-Smirnov testi sonucuna göre, Kültürlerarası Duyarlılık Ölçeği $(Z=1.48, p>.05)$ ve Etnikmerkezcilik Ölçeğinden $(Z=1.37$, $p>.05)$ alınan puanlar normal dağılım göstermektedir. Levene testi sonucuna göre, Kültürlerarası Duyarlılık Ölçeğine ait değerler $(F=.76, p>.05)$ ve Etnikmerkezcilik Ölçeğine ait değerler grupların varyanslarının eşit olduğunu ( $F=2.33, p>.05)$ göstermektedir. Ayrıca, Box's $M$ testi sonucu kovaryans matrislerinin eşit olduğunu $(F=1.13, p>.05)$ göstermektedir. Gerekli koşulların karşılandığı tespit edildikten sonra yapılan MANOVA sonucu Tablo 5'de sunulmaktadır.

Tablo 5.

Öğretmen Adaylarının Mezun Oldukları Lise Türüne Göre Kültürlerarası Duyarlılık ve Etnikmerkezcilik Düzeylerine İlişkin MANOVA Testi Sonucu

$\begin{array}{llllll}\text { Etki } & \text { Değer } & \text { F } & \text { Hipotez } & \text { Hata sd } & \text { P } \\ & & \text { sd } & \\ & & & \end{array}$

\begin{tabular}{lllllll}
\hline Kesişme & $\begin{array}{l}\text { Wilks' } \\
\text { Lambda } \\
(\lambda)\end{array}$ & .00 & 35698 & 2.00 & 308.00 & .00 \\
Lise Türü & $\begin{array}{l}\text { Wilks' } \\
\text { Lambda }\end{array}$ & .95 & 3.67 & 8.00 & 616.00 & .00 \\
& $(\lambda)$ & & & & & \\
\hline
\end{tabular}

Tablo 5'de yer alan MANOVA sonucu, öğretmen adaylarının kültürlerarası duyarlılık ve etnikmerkezcilik puanlarından oluşan doğrusal bileşenden elde edilen puanların mezun oldukları lise türüne göre değiştiğini göstermektedir $(\lambda=.95, F=3.67, p<.05)$. Gruplar Arası Etkileşim Testi anlamlılık değerlerine bakılarak yorumlanmış ve karşılaştırmalarda alfa değeri Bonferroni düzeltmesi doğrultusunda olarak dikkate alınmıştır. Buna göre öğretmen adaylarının kültürlerarası duyarlılık düzeyleri mezun oldukları lise türlerine göre anlamlı bir şekilde farklılık ( $F=5.84, p<.05)$ gösterirken etnikmerkezcilik düzeyleri, mezun oldukları lise türlerine göre anlamlı farklııı göstermemektedir $(F=1.70, p>.05)$.

Kültürlerarası duyarlılık değişkenine göre ortaya çıkan farkın hangi grupların lehine olduğunu belirlemek amacıyla yapılan Scheffe testi sonucuna göre özel lise mezunları ile Anadolul lisesi/süper lise ve düz lise mezunlarının kültürlerarası duyarlılık düzeyleri arasında özel liselerin lehine anlamlı fark bulunmaktadır $(p<.05)$. Diğer grupların karşılaştırılmasında anlamlı fark tespit edilmemiştir $(p>.05)$. 


\section{TARTIŞMA, SONUÇ VE ÖNERILER}

Araştırma bulgularına göre İngilizce Öğretmenliği Bölümü öğretmen adaylarının kültürlerarası duyarlılık düzeylerinin, Türk Dili ve Edebiyatı Bölümü ve Sınıf Öğretmenliği Bölümü öğretmen adaylarından anlamlı bir şekilde yüksek olduğu görülmüştür. Ancak, İngilizce Öğretmenliği Bölümü öğretmen adaylarının ile Din Kültürü ve Ahlak Bilgisi Öğretmenliği Bölümü öğretmen adaylarının puanları arasında anlamlı fark tespit edilmemiştir. Bununla birlikte, kültürlerarası duyarlılık düzeyi en yüksek grup olan, İngilizce Öğretmenliği Bölümü öğretmen adaylarının, etnikmerkezcilik düzeyinin diğer bölümlerin öğrencilerinden anlamlı bir şekilde daha düşük olduğu görülmüştür. İngilizce Öğretmenliği Bölümü öğretmen adaylarından sonra kültürlerarası duyarlılık düzeyi en yüksek ikinci grup olan Din Kültürü ve Ahlak Bilgisi Öğretmenliği Bölümü öğretmen adaylarının etnikmerkezcilik düzeylerinin ise diğer bölümlerin öğrencilerinden anlamlı bir şekilde yüksek olduğu tespit edilmiştir.

İngilizce Öğretmenliği öğrencilerinin kültürlerarası duyarlılık düzeylerinin yüksek olması beklendik bir sonuçtur. Yabancı dil öğretmenlerinin, iki kültürün yan yana getirildiği bir ortamda çok yönlü düşünme, davranma alışkanlığı ve kültürel zenginlik kazanmış olan, yabancı olana hoşgörülü yaklaşabilen, kendi kültürünün bilincinde, ama bu kültürü geniş bir açıdan değerlendirebilen, başka bir deyişle iki kültür arasında önyargısız değerlendirmeler yapabilen kültürlerarası iletişim ilkesini benimsemiş bireyler olmaları öngörülmektedir (Cangil, 2010). Banos (2006) ve Fretheim'ın (1997) yaptıkları araştırmalar sonucu elde ettikleri bulgular, bu sonucu desteklemektedir. Sözü edilen araştırmaların bulgularına göre, en az bir yabancı dil konuşabilen katılımcıların kültürlerarası duyarlılık düzeylerinin hiç yabancı dil bilmeyen katılımcıların kültürlerarası duyarlılık düzeylerinden daha yüksek olduğu görülmüştür. Ayrıca kültürlerarası duyarlılık düzeyleri yüksek olan İngilizce Öğretmenliği Bölümü öğretmen adaylarının etkinmerkezcilik düzeyleri diğer bölüm mezunlarına oranla en düşük olduğu tespit edilmiştir. Alanda yapılan çalışmalar da kültürlerarası duyarlılık düzeyinin artmasıyla etnikmerkezcilik düzeyinin düştüğünü göstermiştir (Neuliep \& diğ., 1997; Dong \& diğ., 2008). Ancak, Din Kültürü ve Ahlak Bilgisi Öğretmenliği Bölümü öğretmen adaylarının en yüksek etnikmerkezcilik düzeyine sahip olmaları beklendik bir sonuç değildir. Çünkü bu öğrenciler, İngilizce Öğretmenliği öğrencilerinden sonra kültürlerarası duyarlılık düzeyleri en yüksek olan öğrencilerdir. Oysa bu araştırmada elde edilen bulgular, kültürlerarası duyarlılık ve etnikmerkezcilik arasında negatif yönde ilişki olduğunu ortaya koymuştur. Bu durumda, kültürlerarası duyarlılık düzeyleri yüksek olan Din Kültürü ve Ahlak Bilgisi Öğretmenliği öğretmen adaylarının etnikmerkezcilik düzeylerinin düşük olması beklenmekteydi. Illköğretim ve ortaöğretim Din Kültürü ve Ahlak Bilgisi öğretim programlarında yer alan genel amaç ve kazanımların birçoğunun, öğrencilerin dünyada farklı yaşam biçimleri, inanışlar, örf ve adetler bulunduğunu fark etmelerini ve bunlara karşı hoşgörülü olmalarını sağlamaya yönelik olduğu görülmektedir. Bu amaçların, Din Kültürü ve Ahlak Bilgisi öğretmen adaylarının eğitimine de etkisi olduğu ve öğretmen adaylarının kültürlerarası duyarlılık düzeylerini olumlu yönde etkilediği düşünülmektedir. Diğer yandan, öğretim programlarında milli kültüre sahip çıkılması, İslâm dininin kültür, dil, sanat, örf ve âdetler üzerindeki etkisi dikkate alınarak İslâm dininin ve bundan kaynaklanan ahlâk anlayışı ile örf ve âdetlerin tanıtılması da hedeflenmiştir (MEB, 2005). Öğretim programlarının içeriği bir bütün olarak ele alındığında din kültürü ve ahlak bilgisi eğitiminin, öğrencilere milli ve evrensel değerleri aynı hassasiyetle aktarmaya çalıştığı söylenebilir. Bu durum, Din Kültürü ve Ahlak Bilgisi öğretmen adaylarının farklılıklara karşı hoşgörülü olduklarını göstermektedir.

Çalışmada elde edilen bulgular, mezun olunan lise türünün öğretmen adaylarının kültürlerarası duyarlılık düzeyleri üzerindeki etkisinin anlamlı; etnikmerkezcilik düzeyleri üzerindeki etkisinin ise anlamlı olmadığını göstermiştir. Bulgulara göre, kültürlerarası duyarlılı düzeyi en yüksek olan grup özel lise mezunlarıdır ve bu liselerden mezun olan öğretmen adaylarının kültürlerarası duyarlıık puanları Anadolu lisesi/süper lise mezunları ve düz lise mezunlarının puanlarından anlamlı düzeyde yüksektir. Yabancı dil eğitiminin kültürlerarası duyarlılığı geliştirme ve etnikmerkezciliği önleme üzerindeki etkisi, özel liselerin mezunlarının kültürlerarası duyarlııı düzeylerinin düz lise mezunlarına göre anlamlı bir şekilde yüksek olmasını açıkladığı söylenebilir.

Öğretmenlerin, toplumların mimarı oldukları düşünüldüğünde, toplumu oluşturan bireylerin sahip olması gereken becerilere önce öğretmenlerin sahip olması gerektiği söylenebilir. Bu bağlamda, eğitim fakültelerinin programlarına kültürlerarası iletişim becerilerini geliştirecek ders içeriklerinin dahil edilmesinin yararlı olacağı 
düşünülmektedir. Bununla birlikte hizmetiçi eğitim yoluyla, ilköğretim ve ortaöğretim kurumlarında görev yapan öğretmenlerin, öğretim programlarında yer alan kültürlerarası becerilere yönelik genel amaç ve kazanımların farkında olmaları ve bu kazanımların en etkili biçimde öğrencilere kazandııımasını sağlayacak yollar üzerinde fikir alışverişinde bulunmalarının faydalı olacağı düşünülmektedir. Ayrıca bu araştırmada nicel veriler ortaya konmuştur. Daha sonraki araştırmalarda nitel yöntemler kullanılarak katılımcıların kültürel farklılıklara yönelik düşünceleri, tutumları belirlenmeye çalışılabilir.

\section{KAYNAKÇA/REFERENCES}

Banos, Ruth Vila. (2006). Intercultural Sensitivity of Teenagers: A study of Educational Necessities in Catalonia. Intercultural Communication Studies. c. 15. s. 2: 16-22.

Bhawuk, D. P. S. , Brislin,R.( 1992). The Measurement of Intercultural Sensitivity Using The Concepts of Individualism and Collectivism. International Journal of Intercultural Relations. c. 16: 413-436.

Bulduk, S., Tosun, H. \& Ardıç, E. (2011). Türkçe Kültürler Arası Duyarlılık Ölçeğinin Hemşirelik Öğrencilerinde Ölçümsel Özellikleri. Türkiye Klinikleri J. Med. Ethics, 19 (1): 25-31.

Büyüköztürk, Ş. (2007). Sosyal Bilimler İçin Veri Analizi El Kitabı. Ankara: Pegem Yayıncılık.

Cangil B. (2010). Kültürlerarası İletişimde Beden Dili", Töder, Tüm Özel Öğretim Kurumları Derneği Dergisi, ss.29-30,

Chen, G., Starosta, W. (1996). Intercultural Communication Competence: A Synthesis. Communication Yearbook. ed. Brant B. Burleson. c. 19: 353-383. California: Sage Publications.

Chen, G., Starosta, W. (2000). The Development and Validation of the Intercultural Sensitivity Scale. Annual Meeting of the National Communication Association, 8-12

November 2000. Seattle.

Coşkun, H. (1996). Eğitim Teknolojisi Açısından Kültürlerarası Eğitim. Ankara: Bizim Büro Basımevi.

Coşkun, H. (2006). Türkiye'de Kültürlerarası Eğitim. Türkiye'de Eğitim Bilimleri: Bir Bilanço Denemesi. 1.bs. ed. Muhsin Hesapçıŏlu, Alpaslan Durmuş. Ankara: Nobel Yayın Dağıtım.

Demir, A., Demir,S. (2009). Erasmus Programının Kültürlerarası Diyalog ve Etkileşim Açısından Değerlendirilmesi: Öğretmen Adaylarıyla Nitel Bir Çalışma. Uluslararası Sosyal Araştırmalar Dergisi. c. 2. s. 9: 95-105.

Dong, Q., Day, K.\& Collaço, C.(2008). Overcoming Ethnocentrism Through Developing Intercultural Communication Sensitivity and Multiculturalism. Human Communication: A Publication of the Pasific and Asian Communication Association. c. 11. s. 1: 27-38.

Eğinli, A.T. (2011). Kültürlerarası Yeterliliğin Kazanılmasında Kültürel Farklılık Eğitimlerinin Önemi. Marmara Üniversitesi Sosyal Bilimler Enstitüsü Dergisi. 9(35): 207-213.

Fretheim, M.(2007). Assesing the Intercultural Sensitivity of Educators in an American International School. Doktora Tezi. Minnesota Üniversitesi.

Jandt, F. E.(1995). Intercultural Communication: An Introduction. California: Sage Publications.

Karasar, N. (2007). Bilimsel Araştırma Yöntemi. Ankara: Nobel Yayın Dağıtım.

Kartarı, A. (2006). Farklılıklarla Yaşamak: Kültürlerarası İletişim. Ankara: Ürün Yayınları.

Üstün, E. (2011). Öğretmen Adaylarının Kültürlerarası Duyarlııı ve Etnikmerkezcilik Düzeylerini Etkileyen Etmenler. Yüksek Lisans Tezi.Yıldız Teknik Üniversitesi

MEB.( 2005). İlköğretim Din Kültürü ve Ahlak Bilgisi Dersi Öğretim Programı. Ankara

Neuliep, J.W., McCroskey, J. (1997). The Development of a U.S. and Generalized Ethnocentrism Scale. Communication Research Reports. c. 14. s. 4: 385-398.

Parekh, B. (2002). Çokkültürlülüğü Yeniden Düşünmek. Ankara: Phoenix Yayınevi.

Penbek, Ş., Yurdakul, D. \& Cerit, A.G. (2009). Intercultural Communication Competence: A Study About The Intercultural Sensitivity of University Students Based on Their Education and International Experiences. European and Mediterranean Conference on Information Systems. 13-14 Haziran 2009. İzmir.

Sumner, W. G. (1906). Folkways. Boston: Athenaeum Press.

Westrick, J. M., Celeste Y., Yuen, M.(2007). The Intercultural Sensitivity of Secondary Teachers in Hong Kong: A Comparative Study with Implications for Professional Development. Intercultural Education. c. 18. s. 2: $129-145$

Iletișim/Correspondence Dr. Serkan DEMIR serkandemir4@gmail.com Elif Üstün ustun-elif@hotmail.com 